Article

\title{
A Flexible Hot-Film Sensor Array for Underwater Shear Stress and Transition Measurement
}

\author{
Baoyun Sun ${ }^{1}$, Pengbin Wang ${ }^{1}{ }^{\circledR}$, Jian Luo ${ }^{1}$, Jinjun Deng ${ }^{1}$, Shiqi Guo ${ }^{2}$ and Binghe Ma ${ }^{1, *}$ \\ 1 Key Laboratory of Micro/Nano Systems for Aerospace, Ministry of Education, Northwestern Polytechnical \\ University, Xi'an 710072, Shaanxi, China; sunbaoyun@mail.nwpu.edu.cn (B.S.); \\ wangpb@mail.nwpu.edu.cn (P.W.); jian.luo@nwpu.edu.cn (J.L.); dengjj@nwpu.edu.cn (J.D.) \\ 2 Department of Electrical and Computer Engineering, George Washington University, Washington, DC 20052, \\ USA; gsq029@gwu.edu \\ * Correspondence: mabh@nwpu.edu.cn; Tel.: +86-029-8849-2847
}

Received: 5 September 2018; Accepted: 11 October 2018; Published: 15 October 2018

check for updates

\begin{abstract}
A flexible hot-film sensor array for wall shear stress, flow separation, and transition measurement has been fabricated and implemented in experiments. Parylene $C$ waterproof layer is vapor phase deposited to encapsulate the sensor. Experimental studies of shear stress and flow transition on a flat plate have been undertaken in a water tunnel with the sensor array. Compared with the shear stress derived from velocity profile and empirical formulas, the measuring errors of the hot-film sensors are less than 5\%. In addition, boundary layer transition of the flat plate has also been detected successfully. Ensemble-averaged mean, normalized root mean square, and power spectra of the sensor output voltage indicate that the Reynolds number when transition begins at where the sensor array located is $1.82 \times 10^{5}, 50 \%$ intermittency transition is $2.52 \times 10^{5}$, and transition finishes is $3.96 \times 10^{5}$. These results have a good agreement with the transition Reynolds numbers, as measured by the Laser Doppler Velocimetry (LDV) system.
\end{abstract}

Keywords: flexible; hot-film sensor; shear stress; transition; underwater

\section{Introduction}

Wall shear stress is one of the most important fluid mechanical parameters in the boundary layer, which is a tangential force in the direction of motion due to the viscosity of the fluid [1,2]. The time averaged value of shear stress indicates the local shin friction drag, its measurement is essential for aerodynamic performance optimization of aircraft and drag reduction of underwater vehicle. The time resolved value of shear stress can be used to analyze the flow fluctuation, like vortex structure, coherent portion of turbulence, and so on [3]. Thus, the accurate and time-resolved measurement of shear stress is critical for a physical understanding of complex flow phenomena and assisting in their control [4].

Transition from laminar to turbulent flow drastically changes the skin friction drag, aerodynamic/ hydrodynamic noise, vortex structure, and heat transfer rate of fluids, yet when and how turbulence emerges is complicated even for simple flow. Due to its fundamental importance to the research of fluid motions, the transition phenomenon has received and continues to attract much attention. A great deal of theoretical and experimental work has been done on the instability of laminar boundary layers and in determining criteria for transition [5-8]. Because there are so many factors affecting transition, no satisfactory theory for the transition process in any flow condition has been established so far. Hence, the ability to experimentally determine transition Reynolds number and location is very important for turbulence studies.

Over the last few decades, various methods have been developed for shear stress measurement [9-11], such as Preston or Stanton tubes, laser Doppler anemometers, sublayer fence, 
floating element sensors, and hot-wire or hot-film probes, etc. Among all of these approaches, the flexible hot-film sensor fabricate on polymer substrate with a waterproof cover is most suitable for underwater shear stress and transition measurements, since it has good water resistance, high temporal/spatial resolution, less interference to the flow, and is well fit on curved surfaces.

Many qualitative flow separation and transition detection with hot-film sensors have been conducted in the air [12-15]. However, these flow phenomena measurement experiments can hardly be seen in the water, especially quantitative shear stress measurement and flow transition detection. In this paper, a flexible hot-film sensor array with deposited Parylene $C$ as the waterproof cover layer is developed for underwater flow measurement. The quantitative shear stress and transition measurement experiments on a flat plate were conducted in a water tunnel. The results have a good agreement with the empirical formulas and Laser Doppler Velocimetry (LDV) velocity profile.

\section{Flexible Hot-Film Sensor}

\subsection{Working Principle}

Basically, a hot-film sensor makes use of the principle of heat transfer from a thermistor heated by current to the passing flow [16]. As shown in Figure 1, the heat generated by the thermistor dissipated into the ambient in three ways, heat convection to the flow $\left(\mathrm{Q}_{1}\right)$, heat conduction to the substrate $\left(\mathrm{Q}_{2}\right)$, and heat radiation $\left(\mathrm{Q}_{3}\right)$, while the heat radiation can be neglected. The rate of heat loss from the heated thermistor to the flow is dependent on the velocity profile in the boundary layer. The wall shear stress $\tau_{\mathrm{w}}$ generated by the flow is expressed as [1],

$$
\tau_{\mathrm{w}}=\mu \frac{\partial \mathrm{U}}{\partial \mathrm{y}}
$$

where $\mu$ is the fluid's viscosity, $\partial \mathrm{U} / \partial \mathrm{y}$ is the mean streamwise velocity gradient at the wall. As the temperature of the thermistor varies with changes of the velocity gradient in the boundary layer, so does the resistance. Thus, we can obtain the shear stress by means of the sensor output voltage indirectly.

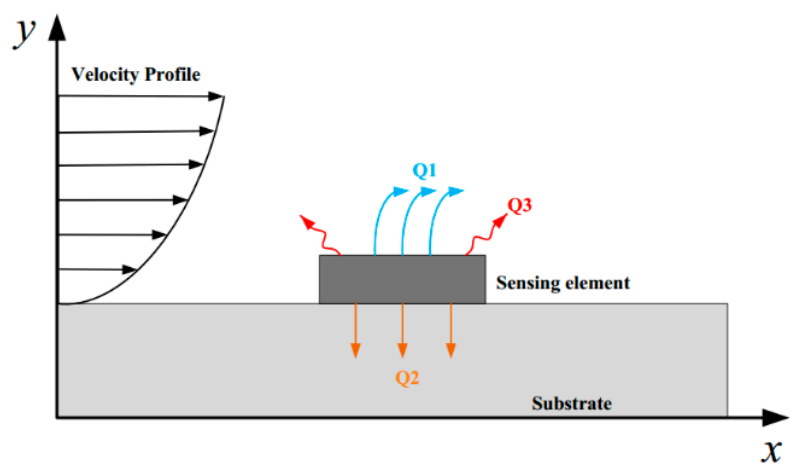

Figure 1. Schematic view of the hot-film sensor working principle.

The relationship between the shear stress $\tau$ and input power $P$ to the sensor is typically described by the following empirical equation $[17,18]$,

$$
\mathrm{P}=\frac{\mathrm{U}^{2}}{\mathrm{R}}=\Delta \mathrm{T}\left[\mathrm{A}_{\mathrm{t}}(\rho \tau)^{\frac{1}{\mathrm{~m}}}+\mathrm{B}_{\mathrm{t}}\right]
$$

where $\mathrm{U}$ and $\mathrm{R}$ are the output voltage and the resistance of the shear stress sensor at the operating temperature $\mathrm{T}$, respectively. $\Delta \mathrm{T}$ is the temperature difference between the sensor operating temperature $T$ and fluid $T_{f}, \rho$ is the density of the fluid, $A_{t}, B_{t}$, and $m$ are usually determined by calibration. When the 
sensor working in constant current (CC) mode, the input current I is constant. According to ohm's law, $\mathrm{U}=\mathrm{IR}$. Equation (2) can be expressed as,

$$
\mathrm{UI}=\left(\mathrm{T}-\mathrm{T}_{\mathrm{f}}\right)\left[\mathrm{K}_{1} \tau^{\mathrm{n}}+\mathrm{K}_{2}\right],
$$

where $K_{1}=A_{t} \rho^{1 / m}, K_{2}=B_{t}, n=1 / m$. When the shear stress is zero, we have

$$
\mathrm{U}_{0} \mathrm{I}=\left(\mathrm{T}_{0}-\mathrm{T}_{\mathrm{f}}\right) \mathrm{K}_{2} .
$$

where $\mathrm{T}_{0}$ is the operating temperature when the shear stress is zero, $\mathrm{U}_{0}$ is the output voltage at the operating temperature $T_{0}$. Hence, the temperature difference between $T_{0}$ and $T$ can be derived from Equations (3) and (4),

$$
\mathrm{T}_{0}-\mathrm{T}=\mathrm{I}\left(\frac{\mathrm{U}_{0}}{\mathrm{~K}_{2}}-\frac{\mathrm{U}}{\mathrm{K}_{1} \tau^{\mathrm{n}}+\mathrm{K}_{2}}\right) .
$$

The temperature coefficient of resistance (TCR) $\alpha$ is an important parameter for the operation of the thermal shear stress sensor, which is given by,

$$
\alpha=\frac{\mathrm{R}-\mathrm{R}_{\mathrm{ref}}}{\left(\mathrm{T}-\mathrm{T}_{\mathrm{ref}}\right) \mathrm{R}_{\mathrm{ref}}},
$$

where $R$ is the resistance at temperature $T, R_{\text {ref }}$ is the reference resistance at reference temperature $T_{\text {ref }}$. So, the resistance $R$ at operating temperature $T$ and the resistance $R_{0}$ at operating temperature $T_{0}$ can be described by the following Equations (7) and (8), respectively.

$$
\begin{gathered}
\mathrm{R}=\mathrm{R}_{\text {ref }}\left[1+\alpha\left(\mathrm{T}-\mathrm{T}_{\text {ref }}\right)\right], \\
\mathrm{R}_{0}=\mathrm{R}_{\text {ref }}\left[1+\alpha\left(\mathrm{T}_{0}-\mathrm{T}_{\text {ref }}\right)\right] .
\end{gathered}
$$

The temperature difference between $\mathrm{T}_{0}$ and $\mathrm{T}$ can also be derived from Equations (7) and (8),

$$
\mathrm{T}_{0}-\mathrm{T}=\frac{\mathrm{R}_{0}-\mathrm{R}}{\mathrm{R}_{\mathrm{ref}} \alpha}=\frac{\mathrm{I}\left(\mathrm{R}_{0}-\mathrm{R}\right)}{\mathrm{IR}_{\mathrm{ref}} \alpha}=\frac{\mathrm{U}_{0}-\mathrm{U}}{\mathrm{IR}_{\mathrm{ref}} \alpha} .
$$

Finally, the relationship between $U$ and $U_{0}$ can be derived from Equations (5) and (9),

$$
\mathrm{U}=\mathrm{U}_{0}-\frac{\mathrm{A} \tau^{\mathrm{n}}}{1+\mathrm{B} \tau^{\mathrm{n}}},
$$

where $\mathrm{A}=\frac{\mathrm{U}_{0} \mathrm{~K}_{1}}{\mathrm{~K}_{2}\left(\mathrm{I}^{2} \mathrm{R}_{\text {ref }} \alpha \mathrm{K}_{2}-1\right)}, \mathrm{B}=\frac{\mathrm{I}^{2} \mathrm{R}_{\text {ref }} \alpha \mathrm{K}_{1}}{\mathrm{I}^{2} \mathrm{R}_{\text {ref }} \alpha \mathrm{K}_{2}-1}$.

\subsection{Fabrication}

The fabrication processes of the flexible hot-film sensor array are shown in Figure 2 [19]. A ready-made polyimide (PI) foil in the thickness of $50 \mu \mathrm{m}$ is used as the sensor substrate. It is affixed onto a glass wafer by using a polydimethylsiloxane (PDMS) adhesive layer (b), which is spun-on the wafer. Thermal sensing nickel (Ni) layer of $1 \mu \mathrm{m}$ is then magnetron sputtered (c) onto the cleaned PI foil. With a $200 \mathrm{~nm}$ thick sputtered copper seed layer (d), the copper tracks layer is electroplated (e) to $2 \mu \mathrm{m}$. Then a first photolithography step is carried out and the tracks are wet-etched (f). Afterwards, the sensing elements are patterned with a second photolithography and wet-etched processes $(\mathrm{g})$. The sensing element is $3 \mathrm{~mm}$ long and $50 \mu \mathrm{m}$ wide. Finally, the sensor array is released from the glass (h). The fabricated sensor array with eight sensors is shown in Figure 3. 


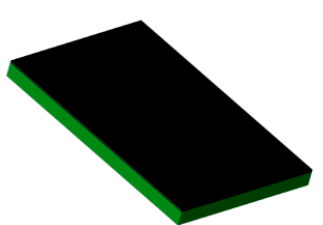

(a)

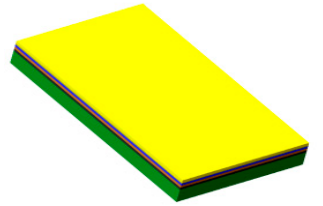

(e)

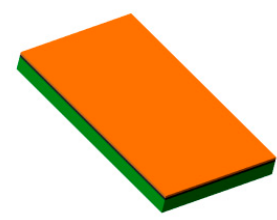

(b)

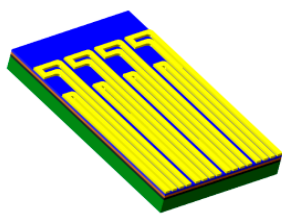

(f)

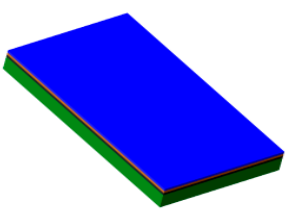

(c)

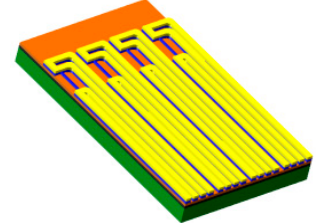

(g)

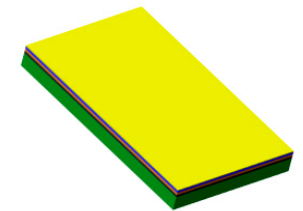

(d)

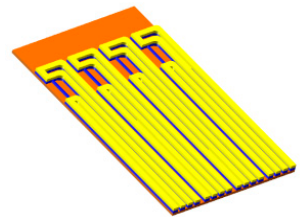

(h)

Figure 2. Fabrication processes of the flexible hot-film sensor array.

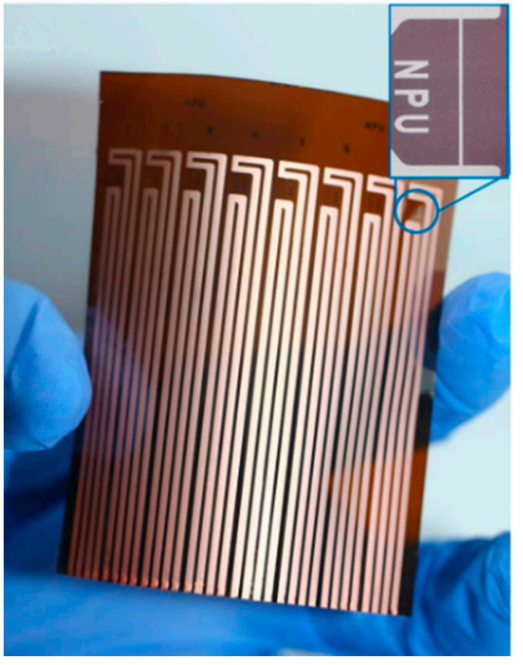

Figure 3. Flexible hot-film sensor array with eight sensors.

The sensor sensitivity and dynamic characteristic is proportional to the TCR [20]. Hence, to reach a better sensor performance, the value of TCR must be as high as possible. Vacuum thermal annealing is carried out to improve the TCR value and to eliminate lattice defects in Ni film. The sensor is kept in a high-vacuum furnace, the temperature increased to $400{ }^{\circ} \mathrm{C}$ within $120 \mathrm{~min}$ and kept constant for $360 \mathrm{~min}$.

To operate under water, a waterproof layer needs to be deposited to encapsulate the sensor. Parylene $C$ is chosen as the waterproof material due to its small moisture transmission [21]. $2 \mu \mathrm{m}$ thick Parylene $C$ waterproof layer is vapor phase deposited. Underwater shear stress and transition measurements that are introduced in the following chapters validate the reliability of Parylene $\mathrm{C}$ as a waterproof layer.

\subsection{Calibration}

The sensor array calibration was carried out in a water tunnel. The schematic drawing of the water tunnel facility is shown in Figure 4, it mainly consists of upstream and downstream water tanks, water pump, electromagnetic flowmeter, and test section. The test section channel has a length of $2600 \mathrm{~mm}$, a width of $250 \mathrm{~mm}$, and a height of $20 \mathrm{~mm}$. The wall shear-stress in the channel is obtained from the measurement of the pressure gradient along its length. As illustrated in Figure 5, there are 23 pressure taps that are distributed uniformly at the lower wall of the test section. The first tap is 
$75 \mathrm{~mm}$ from the inlet of the test section, and the distance between every two neighboring taps is $100 \mathrm{~mm}$. The shear stress can be calculated by the following equation,

$$
\tau_{\mathrm{w}}=\frac{\mathrm{h}}{2} \frac{\mathrm{dp}}{\mathrm{dx}},
$$

where $\mathrm{h}$ is the height of the channel, $\mathrm{dp} / \mathrm{dx}$ is the differential pressure drop. We have conducted CFD simulations and LDV measurements about the shear stress and flow development in the test section before. The shear stress measured by pressure gradient have a good agreement with the numerical simulation and LDV results [22,23].

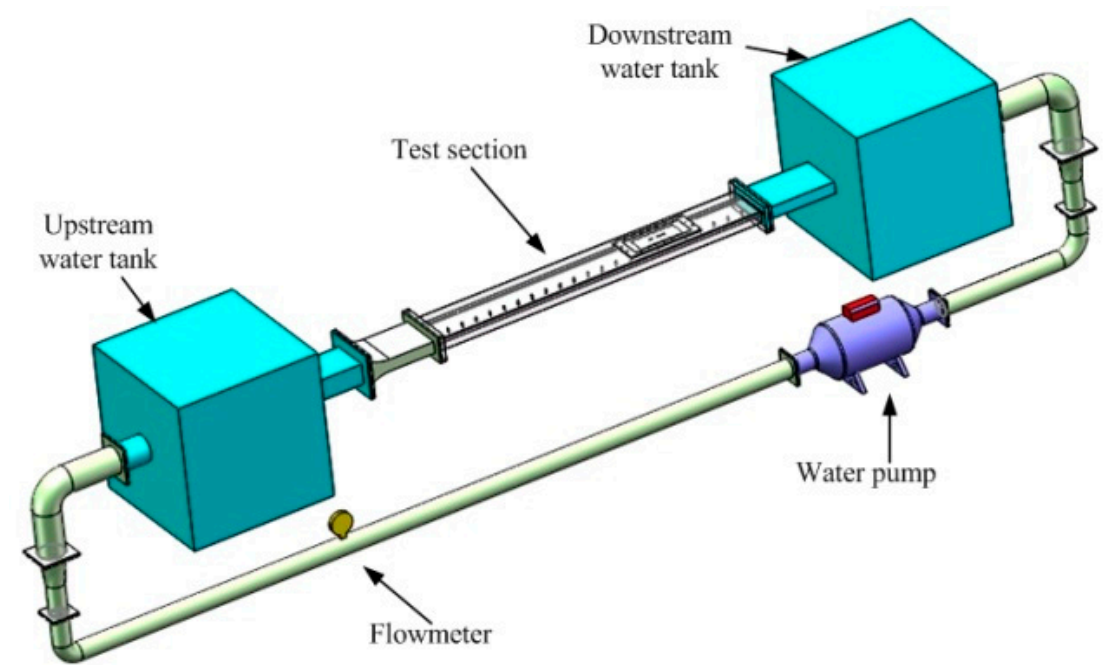

Figure 4. Schematic diagram of the water tunnel.

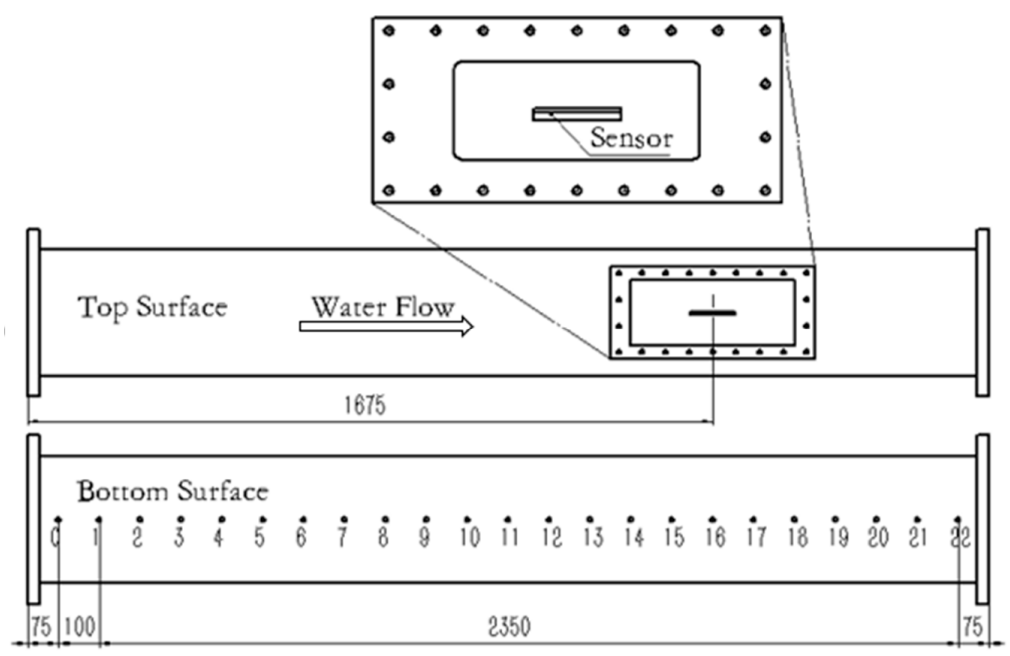

Figure 5. Schematic drawing of the test section.

In the calibration experimental setup, the sensors were surface-flush mounted on the center line of the upper wall of the test section (Figure 5). The eight sensors in the array were located from $1654 \mathrm{~mm}$ (sensor 1) to $1696 \mathrm{~mm}$ (sensor 8) from the inlet of the test section, and the space between two neighboring sensors is $6 \mathrm{~mm}$. These distances from the inlet of the test section to the sensors are sufficient to ensure that the flow is fully developed and effectively two-dimensional [22,23]. The hot-film sensors were working under CC mode, and the driving current were $50 \mathrm{~mA}$. The steady-state sensor output voltages were measured by a data acquisition system (National Instruments) with a sampling frequency of $12 \mathrm{kHz}$ for $8 \mathrm{~s}$. The water temperature was $16^{\circ} \mathrm{C}$ and unchanged during the calibration. The pressure difference with various velocities is shown in Figure 6. 


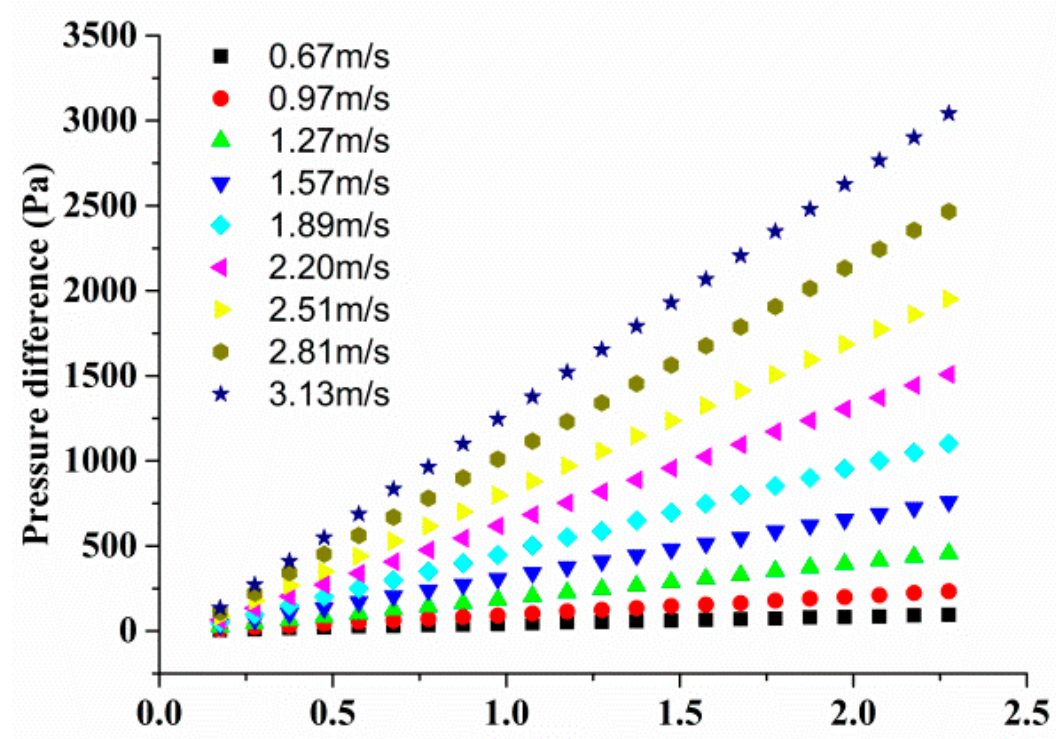

Figure 6. Pressure difference with various velocities.

The calibration curves of sensor 2, sensor 4, sensor 5, and sensor 7 are shown in Figure 7, respectively. According to Equation (10), the relationship between voltage change $\Delta \mathrm{U}(\mathrm{V})$ and shear stress $\tau_{\mathrm{w}}(\mathrm{Pa})$ can be expressed by the following equations,

$$
\begin{aligned}
& \text { Sensor 2: } \Delta \mathrm{U}=\frac{0.1498 \tau_{\mathrm{w}}^{0.9963}}{1+2.807 \tau_{\mathrm{w}}^{0.9963}}, \\
& \text { Sensor } 4: \Delta \mathrm{U}=\frac{0.15 \tau_{\mathrm{w}}^{0.956}}{1+2.733 \tau_{\mathrm{w}}^{0.956}}, \\
& \text { Sensor } 5: \Delta \mathrm{U}=\frac{0.151 \tau_{\mathrm{w}}^{0.928}}{1+2.662 \tau_{\mathrm{w}}^{0.928}}, \\
& \text { Sensor } 7: \Delta \mathrm{U}=\frac{0.1542 \tau_{\mathrm{w}}^{0.8912}}{1+2.534 \tau_{\mathrm{w}}^{0.8912}},
\end{aligned}
$$

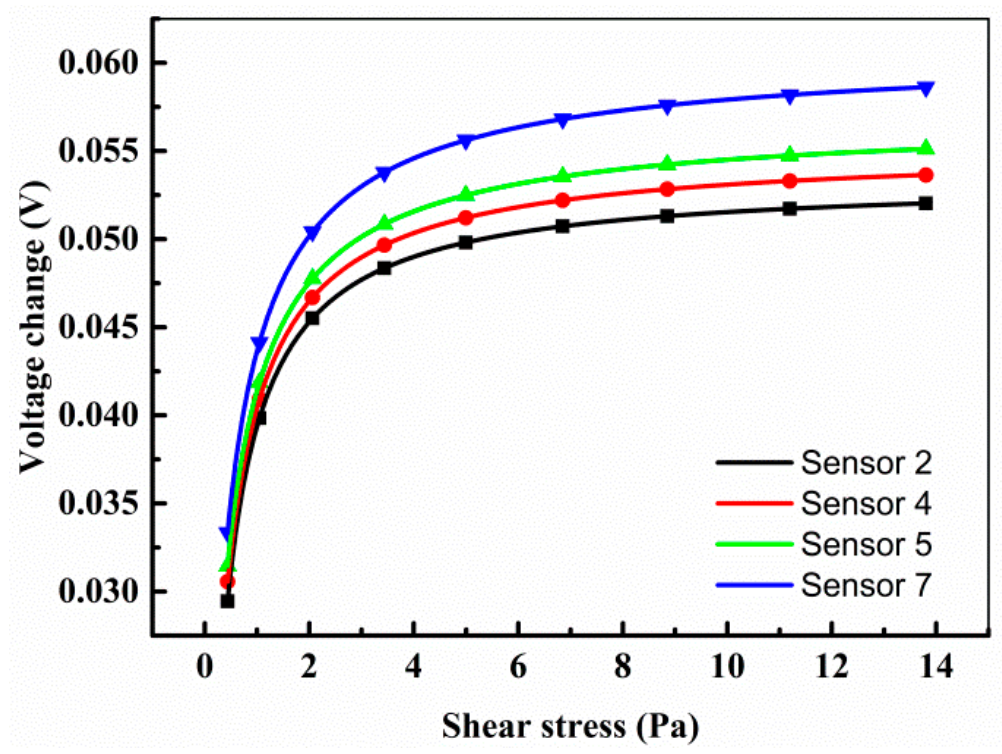

Figure 7. Calibration curves of four sensors. 
The other four sensors have no output signal after we peeled off the sensor array from the test section. After test, the sensors were all still functional, but the welding spots (Figure 8) connecting the sensors and the flexible printed circuit board (FPCB) were broken. These damages were very random and occasional. If we did these works more carefully, then these damages can be avoided. However, the robustness of the welding spots really needs to be improved.

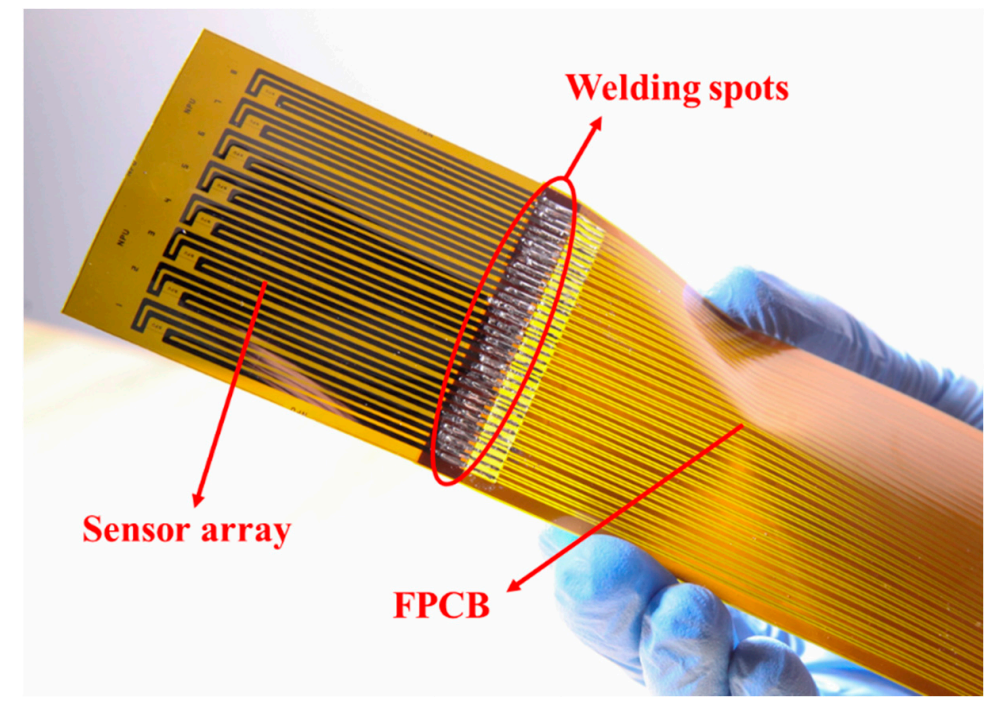

Figure 8. Sensors are connected to the flexible printed circuit board (FPCB) by welding.

\section{Shear Stress Measurement}

Underwater shear stress measurement experiments were conducted in the same water tunnel facility, as illustrated in Figure 4, but the test section has been replaced by a new one. The length of the new test section is $2600 \mathrm{~mm}$, width is $250 \mathrm{~mm}$, and height is $150 \mathrm{~mm}$. A photograph of the flat plate installed in the center of the test section and the hot-film sensor array flush mounted on the flat plate surface are shown in Figure 9. The flat plate has a length of $1000 \mathrm{~mm}$, a width of $150 \mathrm{~mm}$, and a thickness of $20 \mathrm{~mm}$. The angle between the flat plate and the center line of the test section (or the free-stream direction) is $0.34^{\circ}$, which can ensure zero pressure gradient on the flat plate. This angle was determined by pressure measurements. The sensors that were used for shear stress measurement were the calibrated ones in Section 2.3. The sensors were located from $x=780 \mathrm{~mm}$ (sensor 1) to $\mathrm{x}=822 \mathrm{~mm}$ (sensor 8) from the leading edge of the flat plate. Except the flexible hot-film sensors, the LDV system and empirical formulas were also used to measure and calculate the shear stress of the flat plate.

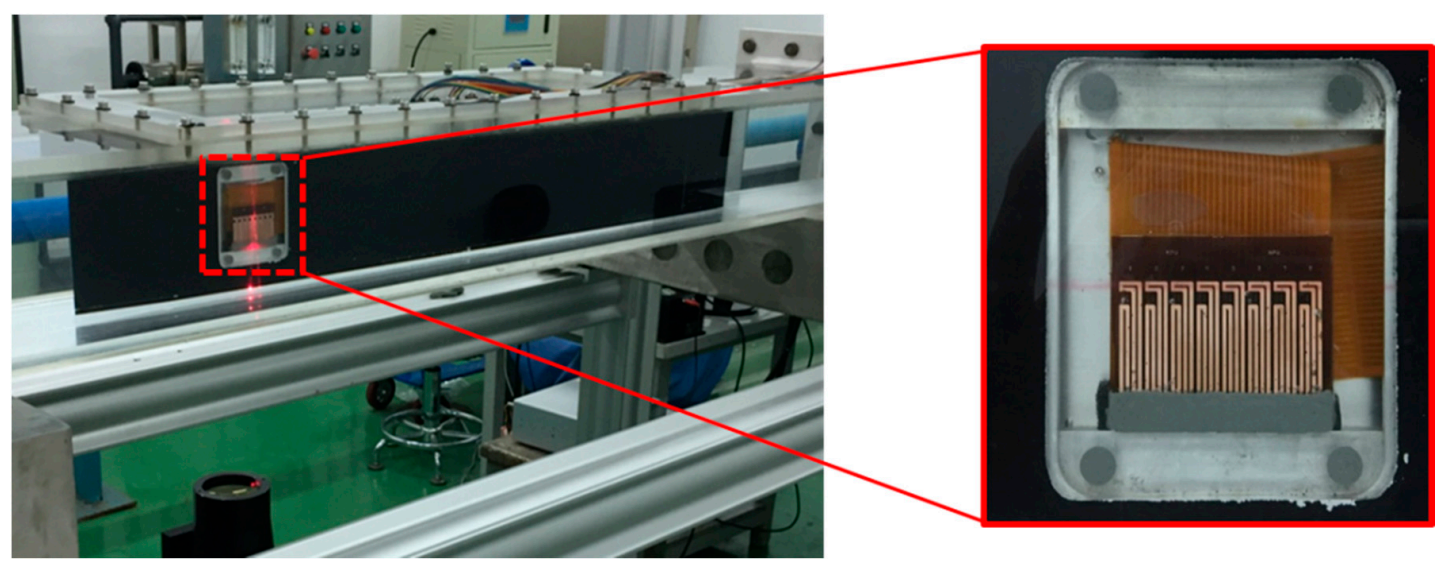

Figure 9. Flexible hot-film sensor array mounted on the flat plate in the water tunnel. 


\subsection{Shear Stress Measurement by Hot-Film Sensors}

The hot-film sensors were working under CC mode, and the driving current were $50 \mathrm{~mA}$. The sensor output voltages with respect to various velocities were measured by a data acquisition system with a sampling frequency of $12 \mathrm{kHz}$ for $8 \mathrm{~s}$. The water temperature was kept at a constant of $16{ }^{\circ} \mathrm{C}$. The velocity gradients at where the sensors mounted were measured by the LDV system. According to Equations (13)-(15), the shear stress $\tau_{\mathrm{w}}(\mathrm{Pa})$ can be obtained by the voltage change $\Delta \mathrm{U}(\mathrm{V})$,

$$
\begin{aligned}
& \text { Sensor } 4: \tau_{\mathrm{w}}=\left(\frac{\Delta \mathrm{U}}{0.15-2.733 \Delta \mathrm{U}}\right)^{\frac{1}{0.956}}, \\
& \text { Sensor } 5: \tau_{\mathrm{w}}=\left(\frac{\Delta \mathrm{U}}{0.151-2.662 \Delta \mathrm{U}}\right)^{\frac{1}{0.928}}, \\
& \text { Sensor } 7: \tau_{\mathrm{w}}=\left(\frac{\Delta \mathrm{U}}{0.154-2.534 \Delta \mathrm{U}}\right)^{\frac{1}{0.891}},
\end{aligned}
$$

the shear stress measured by sensor 4 , sensor 5 and sensor 7 are shown in Table 1 . One lead wire of sensor 2 was damaged during the test, so the data of sensor 2 was invalid.

Table 1. Shear stress measured by hot-film sensors.

\begin{tabular}{cccc}
\hline \multirow{2}{*}{ Velocity $(\mathbf{m} / \mathbf{s})$} & \multicolumn{3}{c}{ Shear Stress $\mathbf{( P a})$} \\
\cline { 2 - 4 } & Sensor $\mathbf{4}(\mathbf{x}=\mathbf{7 9 8} \mathbf{~ m m})$ & Sensor $\mathbf{5}(\mathbf{x}=\mathbf{8 0 4} \mathbf{~ m m})$ & Sensor $\mathbf{7}(\mathbf{x}=\mathbf{8 1 6} \mathbf{~ m m})$ \\
\hline 0.20 & 0.033 & 0.033 & 0.033 \\
0.25 & 0.050 & 0.050 & 0.052 \\
0.30 & 0.108 & 0.101 & 0.106 \\
0.35 & 0.189 & 0.177 & 0.182 \\
0.40 & 0.331 & 0.325 & 0.334 \\
0.45 & 0.453 & 0.466 & 0.459 \\
0.50 & 0.582 & 0.595 & 0.570 \\
0.55 & 0.698 & 0.694 & 0.677 \\
0.60 & 0.782 & 0.783 & 0.780 \\
0.65 & 0.882 & 0.877 & 0.871 \\
0.70 & 0.982 & 0.971 & 0.999 \\
\hline
\end{tabular}

\subsection{Shear Stress Calculated by Empirical Formula}

As known, the three full equations of motion can be reduced to Prandtl's two boundary layer equations for two-dimensional incompressible flow [24],

$$
\begin{gathered}
\frac{\partial \mathrm{u}}{\partial \mathrm{x}}+\frac{\partial v}{\partial \mathrm{y}}=0 \\
\mu \frac{\partial \mathrm{u}}{\partial \mathrm{x}}+\nu \frac{\partial v}{\partial \mathrm{y}}=\mathrm{U} \frac{\mathrm{dU}}{\mathrm{dx}}+\frac{1}{\rho} \frac{\partial \tau}{\partial \mathrm{y}}
\end{gathered}
$$

There are two boundary conditions on $\mathrm{u}$ and one on $\mathrm{v}$ : At $\mathrm{y}=0, \mathrm{u}=v=0$; As $\mathrm{y}=\delta(\mathrm{x})$, $\mathrm{u}=\mathrm{U}(\mathrm{x})$. For laminar flow past the plate, the boundary layer equations can be solved exactly for $\mathrm{u}$ and $v$, assuming that the free-stream velocity $\mathrm{U}$ is constant ( $\mathrm{dU} / \mathrm{dx}=0)$. The solution was by the Blasius equation. The boundary thickness $\delta$ and wall shear stress $\tau_{\mathrm{w}}$ can be governed by the following equations,

$$
\begin{gathered}
\delta=\frac{5.0 \mathrm{x}}{\operatorname{Re}_{\mathrm{x}}^{1 / 2}}, \\
\tau_{\mathrm{w}}=\frac{0.332 \rho \mathrm{U}^{2}}{\operatorname{Re}_{\mathrm{x}}^{1 / 2}} .
\end{gathered}
$$


As there is no exact theory for turbulent boundary layer, two rough empirical formulas we used to calculated turbulent boundary layer thickness and shear stress are as follows [24],

$$
\begin{gathered}
\delta=\frac{0.16 \mathrm{x}}{\operatorname{Re}_{\mathrm{x}}^{1 / 7}}, \\
\tau_{\mathrm{w}}=\frac{0.0135 \rho \mathrm{U}^{2}}{\operatorname{Re}_{\mathrm{x}}^{1 / 7}} .
\end{gathered}
$$

The boundary layer thickness at where sensor 5 located calculated by Equations (21) and (23) are listed in Table 2. The shear stress at where sensor 4, sensor 5, and sensor 7 located calculated by Equations (22) and (24) are listed in Table 3, respectively.

Table 2. Boundary layer thickness calculated by empirical formulas $(x=804 \mathrm{~mm})$.

\begin{tabular}{ccc}
\hline \multirow{2}{*}{ Velocity $(\mathbf{m} / \mathbf{s})$} & \multicolumn{2}{c}{ Boundary Layer Thickness $(\mathbf{m m})$} \\
\cline { 2 - 3 } & Laminar Empirical Formula & Turbulence Empirical Formula \\
\hline 0.20 & 10.49 & 23.43 \\
0.25 & 9.43 & 22.73 \\
0.30 & 8.63 & 22.15 \\
0.35 & 7.97 & 21.66 \\
0.40 & 7.50 & 21.29 \\
0.45 & 7.03 & 20.90 \\
0.50 & 6.70 & 20.61 \\
0.55 & 6.36 & 20.30 \\
0.60 & 6.10 & 20.07 \\
0.65 & 5.85 & 19.83 \\
0.70 & 5.64 & 19.62 \\
\hline
\end{tabular}

Table 3. Shear stress calculated by empirical formulas.

\begin{tabular}{ccccccc}
\hline & \multicolumn{6}{c}{ Shear Stress (Pa) } \\
\cline { 2 - 7 } Velocity (m/s) & \multicolumn{7}{c}{ Laminar Estimation } & \multicolumn{3}{c}{ Turbulence Estimation } \\
\cline { 2 - 7 } & $\mathbf{x = 7 9 8}$ & $\mathbf{x = 8 0 4}$ & $\mathbf{x = 8 1 6}$ & $\mathbf{x = 7 9 8}$ & $\mathbf{x = 8 0 4}$ & $\mathbf{x = 8 1 6}(\mathbf{m m})$ \\
\hline 0.20 & 0.035 & 0.035 & 0.035 & 0.099 & 0.099 & 0.099 \\
0.25 & 0.049 & 0.049 & 0.049 & 0.150 & 0.150 & 0.149 \\
0.30 & 0.065 & 0.064 & 0.064 & 0.210 & 0.210 & 0.210 \\
0.35 & 0.081 & 0.081 & 0.080 & 0.280 & 0.280 & 0.279 \\
0.40 & 0.099 & 0.099 & 0.098 & 0.359 & 0.359 & 0.358 \\
0.45 & 0.119 & 0.118 & 0.117 & 0.447 & 0.446 & 0.445 \\
0.50 & 0.139 & 0.138 & 0.137 & 0.543 & 0.543 & 0.542 \\
0.55 & 0.160 & 0.160 & 0.158 & 0.649 & 0.648 & 0.646 \\
0.60 & 0.183 & 0.182 & 0.181 & 0.762 & 0.761 & 0.760 \\
0.65 & 0.206 & 0.205 & 0.204 & 0.884 & 0.883 & 0.882 \\
0.70 & 0.230 & 0.229 & 0.228 & 1.015 & 1.014 & 1.012 \\
\hline
\end{tabular}

\subsection{Shear Stress Measured by LDV System}

Meanwhile, the velocity profile at where sensor 5 located $(x=804 \mathrm{~mm})$ were obtained by the DANTEC Flow Explorer LDV system, its uncertainty of velocity measurement is about $0.06 \%$. An adequate near-wall resolution in the measurements is essential for an accurate interpretation of the results [25]. The velocity profiles compares with laminar Blasius [26] and turbulent Spalding [27]; velocity profiles are shown in Figure 10a,b, respectively. Hence, the shear stress can be obtained according to Equation (1). On the basis of boundary layer thickness definition [1], we can also get the boundary layer thickness according to the velocity profiles. The boundary layer thickness and shear stress that were calculated by the velocity profiles are shown in Table 4. 


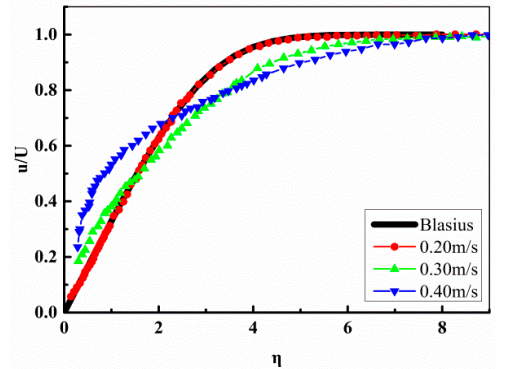

(a)

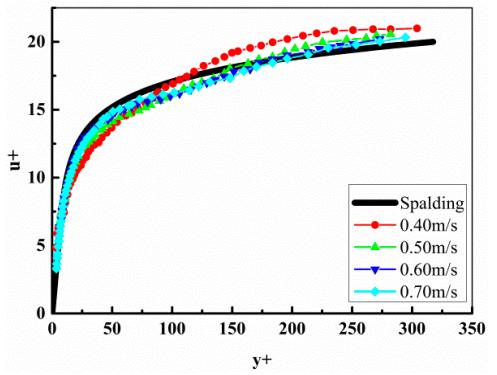

(b)

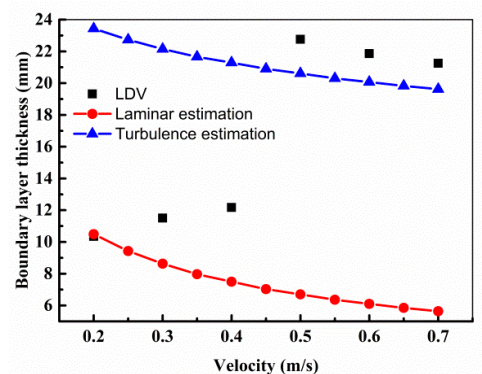

(c)

Figure 10. (a) Velocity profiles obtained by Laser Doppler Velocimetry (LDV) compares with laminar Blasius velocity profile. (b) Velocity profiles obtained by LDV compares with turbulent Spalding velocity profile. (c) Boundary layer thickness calculated by velocity profiles compared with laminar and turbulence empirical formulas values.

Table 4. Boundary layer thickness and shear stress measured by LDV.

\begin{tabular}{ccc}
\hline Velocity $(\mathbf{m} / \mathbf{s})$ & Boundary Layer Thickness $\mathbf{( m m )}$ & Shear Stress $\mathbf{( P a )}$ \\
\hline 0.20 & 10.35 & 0.033 \\
0.30 & 11.50 & 0.108 \\
0.40 & 12.17 & 0.334 \\
0.50 & 22.76 & 0.542 \\
0.60 & 21.86 & 0.763 \\
0.70 & 21.25 & 1.031 \\
\hline
\end{tabular}

The boundary layer thickness derived from the velocity profiles compared with the values calculated by laminar and turbulence empirical formulas are shown in Figure 10c. From Figure 10 we can conclude that when the free-stream velocity is less than $0.2 \mathrm{~m} / \mathrm{s}$, the flow at $\mathrm{x}=804 \mathrm{~mm}$ is laminar. When the velocity is great than $0.5 \mathrm{~m} / \mathrm{s}$, the flow is turbulence. And the flow is laminar to turbulence transition when velocity is greater than $0.2 \mathrm{~m} / \mathrm{s}$ and less than $0.5 \mathrm{~m} / \mathrm{s}$.

The shear stress and its error [28] measured by the hot-film sensors compared with empirical formulas and LDV results were shown in Figure 11. We can see that the shear stress measured by the hot-film sensors are almost equal to the laminar empirical formulas values when the flow is laminar and basically same with the turbulence empirical formulas values when the flow is turbulence. From Figure 11b, we can see that the shear stress measured by sensor $5(x=804 \mathrm{~mm})$ are all same with the LDV results no matter in laminar, transition, and turbulent regions. The measuring errors of the hot-film sensors are less than $5 \%$.

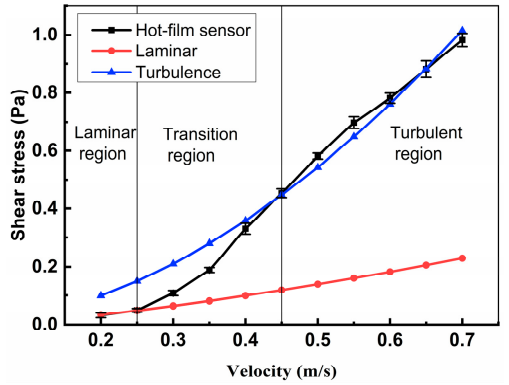

(a)

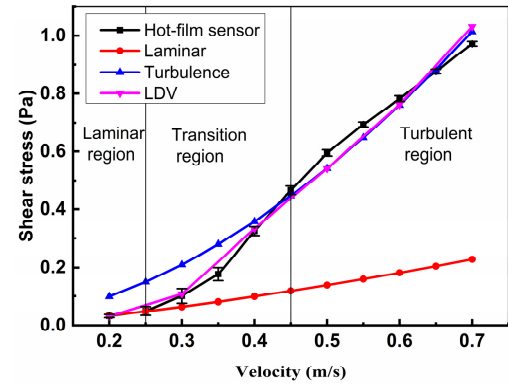

(b)

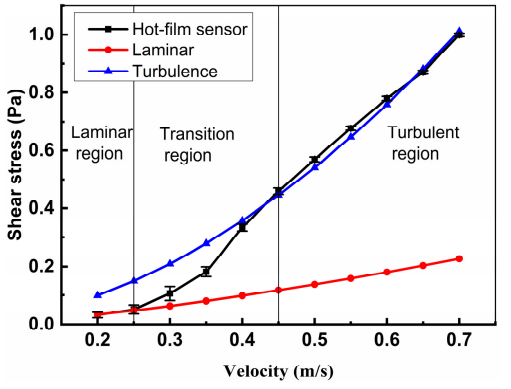

(c)

Figure 11. Shear stress measured by the hot-film sensors compared with the empirical formula and velocity profile. (a) Sensor 4; (b) Sensor 5; and, (c) Sensor 7. 


\section{Transition Measurement}

In addition to quantitative shear stress measurement, the hot-film sensors are also developed to meet the requirements for boundary layer transition detection. The transition experiment facility, flat plate model, and data acquisition system are primarily the same as that described in the last chapter and Figure 9, but the sensor array was replaced by another one with eight functional sensors. The first sensor of the array (sensor 1$)$ is $780 \mathrm{~mm}(\mathrm{x}=780 \mathrm{~mm})$ from the leading edge of the flat plat, and the distance between two adjacent sensors is $6 \mathrm{~mm}$. Sensor 1 was used as a temperature probe to monitor the water temperature, and the other seven sensors were utilized to detect boundary layer transition.

There are three transition Reynolds numbers of interest to be resolved from the hot-film sensor signals [29]. These Reynolds numbers are the onset of transition, the 50\% intermittent, and the end of transition. Characterized by the hot-film sensor output voltages, the beginning of transition is a low amplitude, steady-state signal with very occasional higher amplitude, high frequency bursts. The RMS value of the voltage at this Reynolds number is slightly higher than the RMS value of the lower Reynolds number. The $50 \%$ intermittent of the transition is characterized by large amplitude fluctuations, the RMS value of the signal is greatest. The hot-film signal at the end of transition is very random and moderate. The RMS value of this signal is higher than the laminar, but lower than the $50 \%$ intermittent transition.

Two typical examples of the data for natural transition obtained from sensor $2(x=786 \mathrm{~mm})$ and sensor $8(x=822 \mathrm{~mm})$ are shown in Figure 12a,b, respectively. The RMS values of the fluctuating voltages have been normalized by the mean voltages as an indication of local turbulence level at the respective sensor locations. As seen in Figure 12, the mean voltage changes of sensor 2 and sensor 8 both have an abrupt increase at $U=0.2 \mathrm{~m} / \mathrm{s}\left(\operatorname{Re}=1.82 \times 10^{5}\right)$. Meanwhile, the normalized RMS of sensor 2 and sensor 8 have a sudden increase at $U=0.2 \mathrm{~m} / \mathrm{s}$ and reach a local maximum value at $\mathrm{U}=0.28 \mathrm{~m} / \mathrm{s}\left(\operatorname{Re}=2.52 \times 10^{5}\right)$, and then the RMS dropped sharply until $\mathrm{U}=0.44 \mathrm{~m} / \mathrm{s}\left(\operatorname{Re}=3.96 \times 10^{5}\right)$. When velocity is greater than $0.44 \mathrm{~m} / \mathrm{s}$, the RMS have very little or no change.

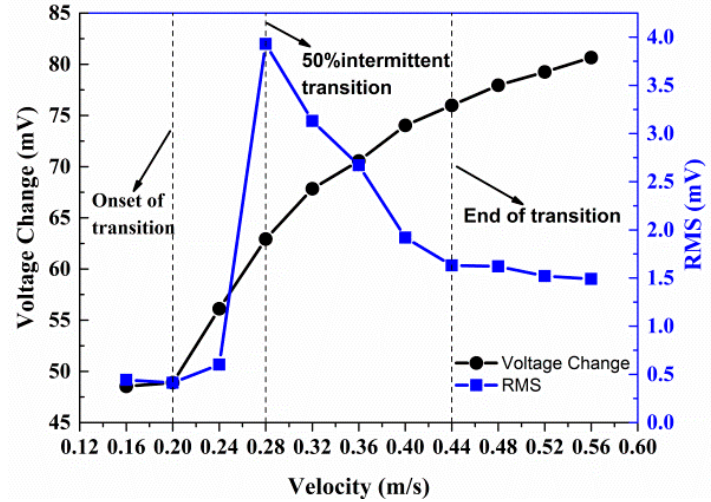

(a)

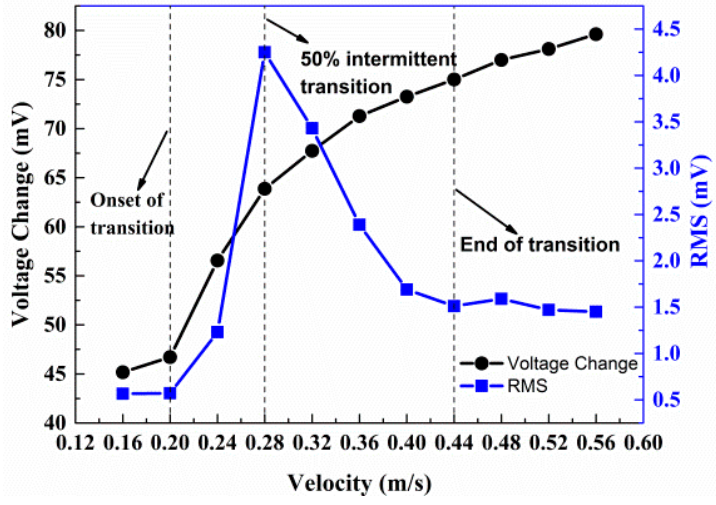

(b)

Figure 12. Voltage changes and RMS values of (a) sensor 2 and (b) sensor 8 .

The voltage changes and RMS of all seven sensors in the array are shown in Figure 13a,b, respectively. The variation tendency of other five sensors are same with sensor 2 and sensor 8 . The voltage changes and RMS both have an abrupt increase at $U=0.2 \mathrm{~m} / \mathrm{s}$. The RMS reach a local maximum value at $U=0.28 \mathrm{~m} / \mathrm{s}$, then dropped sharply until $U=0.44 \mathrm{~m} / \mathrm{s}$. When velocity is greater than $0.44 \mathrm{~m} / \mathrm{s}$, the RMS reach a stable value which is greater than laminar flow and less than $50 \%$ intermittent transition. 


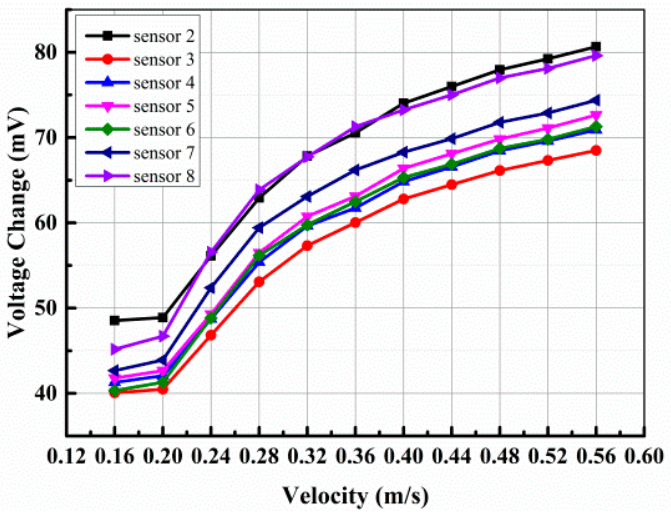

(a)

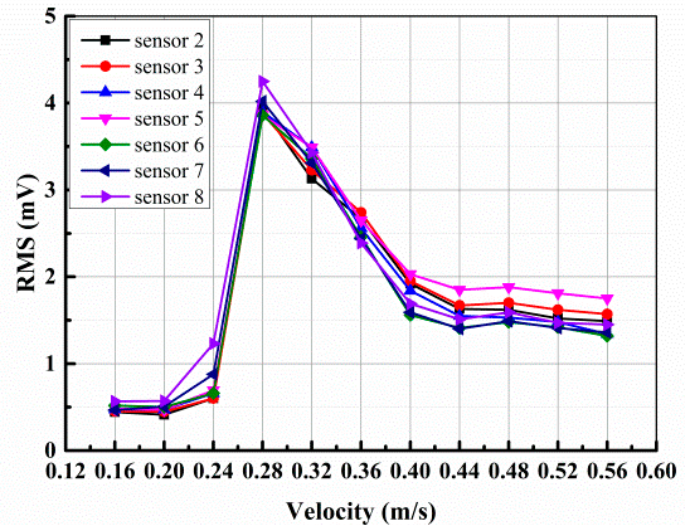

(b)

Figure 13. (a) Voltage change and (b) RMS value of all seven sensors.

In conclusion, at the region where the sensor array located on the flat plate, the transition begins at $\operatorname{Re}=1.82 \times 10^{5}, 50 \%$ intermittent transition happens at $\operatorname{Re}=2.52 \times 10^{5}$ and the transition terminates at $\operatorname{Re}=3.96 \times 10^{5}$.

An AC output voltage-versus-time trace (Figure 14) of sensor 2 at $U=0.28 \mathrm{~m} / \mathrm{s}$ clearly shows the movement of the transition region with time. Although this was actually the $50 \%$ intermittent transition when visually averaged, it is clear that the trace over the $0.1 \mathrm{~s}$ period shows both a laminar and turbulent interval.

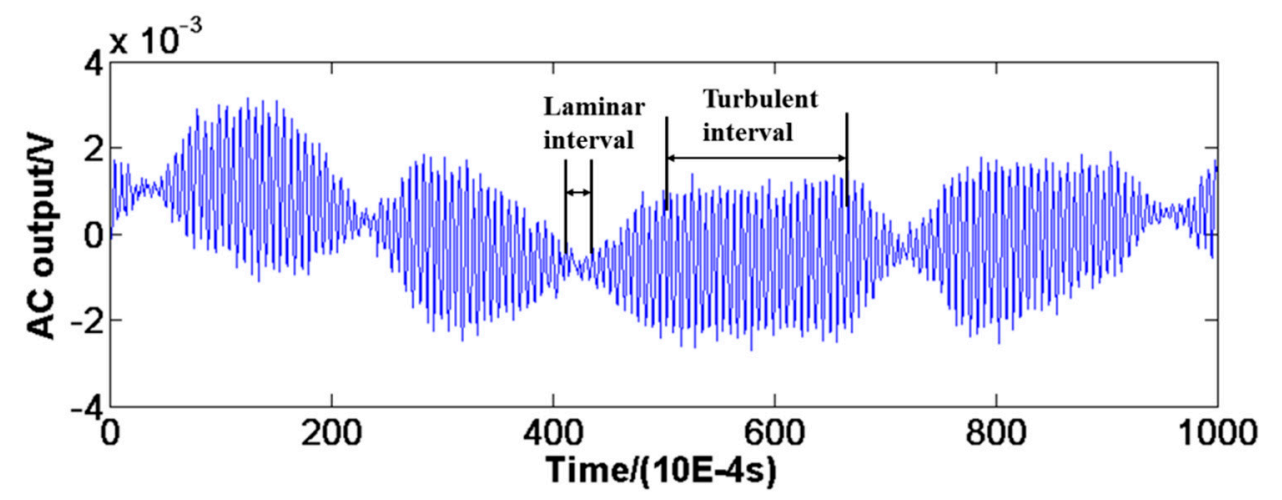

Figure 14. An AC output voltage-versus-time trace of sensor 2 at $U=0.28 \mathrm{~m} / \mathrm{s}$.

A waterfall plot of the spectra (Figure 15) from the voltage-time traces of sensor 2 at different velocities indicate the characteristic shapes of laminar, transitional, and fully turbulent boundary layers. Welch's power spectral density estimate method was employed to analyze the spectra of the output voltage signals, window is 2048 and noverlap is 1024 . The source for the peak in energy at about $50 \mathrm{~Hz}$ that is present at $U=0.16 \mathrm{~m} / \mathrm{s}$ is believed to be associated with power frequency interference, which is easy to be seen in laminar boundary layer spectra. The spectra of the low velocity $(U=0.16 \mathrm{~m} / \mathrm{s})$ shows a significantly low energy level, which is usually associated with a laminar boundary layer. The spectra at $U=0.20 \mathrm{~m} / \mathrm{s}$ indicates the beginning of the transition and shows a marked increase in energy when compared to the lower velocities. The spectra at $U=0.28 \mathrm{~m} / \mathrm{s}$ shows a surge in energy across the spectrum, which is associated with the 50\% intermittency transitional boundary layer. The spectra for the fully turbulent boundary layer $(U=0.44 \mathrm{~m} / \mathrm{s})$ have a litter lower energy level than the 50\% intermittency signal, but the energy is higher than the fully laminar and the onset of transition. 


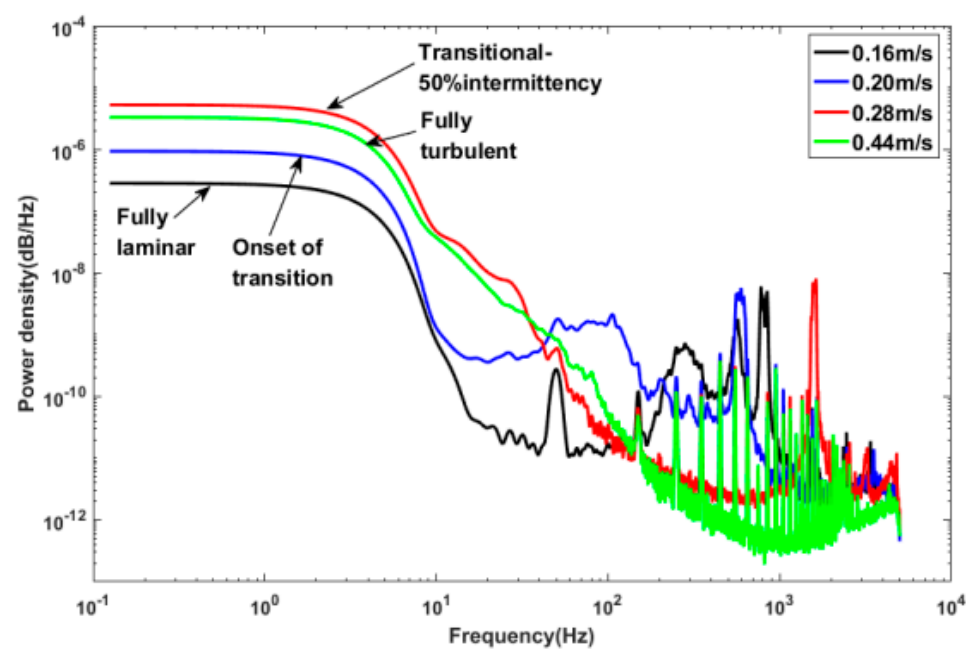

Figure 15. A waterfall plot of the spectra from the voltage-time traces of sensor 2 at different velocities.

\section{Conclusions}

A flexible hot-film sensor array with Parylene $\mathrm{C}$ waterproof layer has been developed for quantitative underwater shear stress measurements. The calibrated hot-film sensors are able to measure the underwater shear stress accurately. Compared with the shear stress values measured by the LDV and calculated by empirical formulas, the measuring errors of the hot-film sensors are less than $5 \%$.

The sensors are also able to detect boundary layer transition, including onset, $50 \%$ intermittency and end of transition by the use of mean voltage change, normalized RMS, and power spectra. The signals of the sensors indicate that the transition on the flat plat begins at $\operatorname{Re}=1.82 \times 10^{5}$, $50 \%$ intermittency transition occurs at $\operatorname{Re}=2.52 \times 10^{5}$, and ends at $\operatorname{Re}=3.96 \times 10^{5}$.

Author Contributions: B.S.; writing—original draft preparation, B.M., J.L. and J.D.; writing—review and editing, P.W.; fabricating the hot-film sensors and preparing the experiments, S.G.; data analysis. All authors read and approved the manuscript.

Funding: This research was funded by the National Instrumentation Program of China, grant number 2013 Y040911 and the National Natural Science Foundation of China, grant number 51775446.

Acknowledgments: The authors would appreciate for the generous supports from Yukui Tian and Xuan Zhang, from National Key Laboratory of Science and Technology on Hydrodynamics, China Ship Scientific Research Center.

Conflicts of Interest: The authors declare no conflict of interest.

\section{References}

1. Schlichting, H.; Gersten, K. Boundary-Layer Theory; Springer: Berlin, Germany, 2016.

2. Vinuesa, R.; Schlatter, P.; Nagib, H.M. Role of data uncertainties in identifying the logarithmic region of turbulent boundary layers. Exp. Fluids 2014, 55, 1751. [CrossRef]

3. Löfdahl, L.; Gadelhak, M. MEMS-based pressure and shear stress sensors for turbulent flows. Meas. Sci. Technol. 1999, 10, 665. [CrossRef]

4. Haritonidis, J.H. The measurement of wall shear stress. In Advances in Fluid Mechanics Measurements; Springer: Berlin/Heidelberg, Germany, 1989; pp. 229-261.

5. Tani, I. Boundary-layer transition. Annu. Rev. Fluid Mech. 1969, 1, 169-196. [CrossRef]

6. Kachanov, Y.S. Physical mechanisms of laminar-boundary-layer transition. Annu. Rev. Fluid Mech. 1994, 26, 411-482. [CrossRef]

7. Eckhardt, B.; Schneider, T.M.; Hof, B.; Westerweel, J. Turbulence Transition in Pipe Flow. Annu. Rev. Fluid Mech. 2007, 39, 447-468. [CrossRef]

8. Mullin, T. Experimental studies of transition to turbulence in a pipe. Annu. Rev. Fluid Mech. 2011, 43, 1-24. [CrossRef] 
9. Winter, K. An outline of the techniques available for the measurement of skin friction in turbulent boundary layers. Prog. Aerosp. Sci. 1979, 18, 1-57. [CrossRef]

10. Fernholz, H.; Janke, G.; Schober, M.; Wagner, P.; Warnack, D. New developments and applications of skin-friction measuring techniques. Meas. Sci. Technol. 1996, 7, 1396. [CrossRef]

11. Sheplak, M.; Cattafesta, L.; Nishida, T.; McGinley, C. MEMS shear stress sensors: Promise and progress. In Proceedings of the 24th AIAA Aerodynamic Measurement Technology and Ground Testing Conference, Portland, OR, USA, 28 June-1 July 2004; p. 2606.

12. Bellhouse, B.J.; Schultz, D.L. Determination of mean and dynamic skin friction, separation and transition in low-speed flow with a thin-film heated element. J. Fluid Mech. 2006, 24, 379-400. [CrossRef]

13. Owen, F.K. Transition experiments on a flat plate at subsonic and supersonic speeds. AIAA J. 2015, 8, 518-523. [CrossRef]

14. Jiang, F.; Lee, G.B.; Tai, Y.C.; Ho, C.M. A flexible micromachine-based shear-stress sensor array and its application to separation-point detection. Sens. Actuators A Phys. 2000, 79, 194-203. [CrossRef]

15. Sun, B.; Ma, B.; Yan, Y.; Jiang, C.; Yuan, W.; Xue, X.; Liu, G.; Fang, Y. A flexible hot-film shear stress sensor array and its application to airfoil separation detection. Sensors 2017, 2017, 1-3.

16. Kuo, J.T.W.; Yu, L.; Meng, E. Micromachined Thermal Flow Sensors-A Review. Micromachines 2012, 3, 550-573. [CrossRef]

17. Yong, X.; Qiao, L.; Guoyu, L.; Katragadda, R.B.; Fukang, J.; Tung, S.; Yu-Chong, T. Micromachined thermal shear-stress sensor for underwater applications. J. Microelectromech. Syst. 2005, 14, 1023-1030. [CrossRef]

18. Haritonidis, J.H. The measurement of wall shear stress. Adv. Fluid Mech. Meas. 1989, 45, 229-261.

19. Sun, B.; Ma, B.; Luo, J.; Li, B.; Jiang, C.; Deng, J. Sensing Elements Space Design of Hot-Film Sensor Array Considering Thermal Crosstalk. Sens. Actuators A Phys. 2017, 265, 217-223. [CrossRef]

20. Wang, J.-J.; Hu, H.; Shang, C.-H. Effect of annealing on the performance of nickel thermistor on polyimide substrate. Thin Solid Films 2017, 632, 28-34. [CrossRef]

21. Xu, Y.; Lin, Q.; Lin, G.; Katragadda, R.B.; Jiang, F.; Tung, S.; Tai, Y.C. Micromachined thermal shear-stress sensor for underwater applications. J. Microelectromech. Syst. 2005, 14, 1023-1030.

22. Huang, H.; Sun, H.; Tian, Y.; Zhang, N.; Xie, H.; Shen, X. CFD analysis and experimental validation on the scheme of calibration for MEMS wall shear stress sensors array for underwater applications. J. Exp. Fluid Mech. 2016, 30, 79-83 and 102.

23. Tian, Y.; Hua, X.; Huang, H.; Sun, H.; Nan, Z.; Xue, S. Calibration of MEMS wall shear-stress-sensors array for underwater applications. J. Exp. Fluid Mech. 2015, 29, 8-12 and 25.

24. Daugherty, R.L.; Ingersoll, A.C. Fluid Mechanics; McGraw-Hill: New York, NY, YSA, 1954; p. 1233.

25. Vinuesa, R.; Duncan, R.D.; Nagib, H.M. Alternative interpretation of the Superpipe data and motivation for CICLoPE: The effect of a decreasing viscous length scale. Eur. J. Mech. B Fluids 2016, 58, 109-116. [CrossRef]

26. Tamaki, H. On the Solution of the Laminar Boundary Layer Equations. Rep. Inst. Sci. Technol. Univ. Tokyo 2006, 5, 49-62.

27. Spalding, D.B. A Single Formula for the "Law of the Wall". Trans. ASME J. Appl. Mech. 1961, 28, 455-458. [CrossRef]

28. Rezaeiravesh, S.; Vinuesa, R.; Liefvendahl, M.; Schlatter, P. Assessment of uncertainties in hot-wire anemometry and oil-film interferometry measurements for wall-bounded turbulent flows. Eur. J. Mech. $B$ Fluids 2018, 72, 57-73. [CrossRef]

29. Johnson, C.B.; Carraway, D.L. A transition detection study at Mach 1.5, 2.0 and 2.5 using a micro-thin hot-film system. In Proceedings of the International Congress on Instrumentation in Aerospace Simulation Facilities, Gottingen, Germany, 18-21 September 1989; pp. 82-94.

(C) 2018 by the authors. Licensee MDPI, Basel, Switzerland. This article is an open access article distributed under the terms and conditions of the Creative Commons Attribution (CC BY) license (http:/ / creativecommons.org/licenses/by/4.0/). 